\title{
Mechanisms underlying synergy between DNA topoisomerase I-targeted drugs and mTOR kinase inhibitors in NF1-associated malignant peripheral nerve sheath tumors
}

\author{
Dong Hyuk Ki $\mathbb{1}^{1,2} \cdot$ Felix Oppel $\mathbb{1}^{1,2} \cdot$ Adam D. Durbin $\mathbb{(}^{1,2,3} \cdot$ A. Thomas Look $\mathbb{C}^{1,2}$
}

Received: 14 November 2018 / Revised: 8 May 2019 / Accepted: 27 May 2019 / Published online: 23 August 2019

(c) The Author(s) 2019. This article is published with open access

\begin{abstract}
Malignant peripheral nerve sheath tumors (MPNSTs) are soft-tissue sarcomas that frequently arise in patients with neurofibromatosis type 1 (NF1). Most of these tumors are unresectable at diagnosis and minimally responsive to conventional treatment, lending urgency to the identification of new pathway dependencies and drugs with potent antitumor activities. We therefore examined a series of candidate agents for their ability to induce apoptosis in MPNST cells arising in nfl/tp53-deficient zebrafish. In this study, we found that DNA topoisomerase I-targeted drugs and mTOR kinase inhibitors were the most effective single agents in eliminating MPNST cells without prohibitive toxicity. In addition, three members of these classes of drugs, either AZD2014 or INK128 in combination with irinotecan, acted synergistically to induce apoptosis both in vitro and in vivo. In mechanistic studies, irinotecan not only induces apoptosis by eliciting a DNA damage response, but also acts synergistically with AZD2014 to potentiate the hypophosphorylation of 4E-BP1, a downstream target of mTORC1. Profound hypophosphorylation of 4E-BP1 induced by this drug combination causes an arrest of protein synthesis, which potently induces tumor cell apoptosis. Our findings provide a compelling rationale for further in vivo evaluation of the combination of DNA topoisomerase I-targeted drugs and mTOR kinase inhibitors against these aggressive nerve sheath tumors.
\end{abstract}

\section{Introduction}

Malignant peripheral nerve sheath tumors (MPNSTs) are aggressive, often metastatic soft-tissue sarcomas associated with neurofibromatosis type 1 (NF1) [1], an autosomal genetic dominant disorder with an incidence of 1 per 3000 individuals [2]. MPNSTs arise in adolescence or early adulthood in NF1 patients, with $65-88 \%$ of the tumors

Supplementary information The online version of this article (https:// doi.org/10.1038/s41388-019-0965-5) contains supplementary material, which is available to authorized users.

A. Thomas Look

Thomas_Look@dfci.harvard.edu

1 Department of Pediatric Oncology, Dana-Farber Cancer Institute, Harvard Medical School, Boston, MA 02115, USA

2 Division of Pediatric Hematology/Oncology Boston Children's Hospital, Boston, MA 02115, USA

3 The Broad Institute of MIT and Harvard, Cambridge, MA 02142, USA developing from benign plexiform neurofibromas [3, 4]. As many as $57 \%$ of NF1 patients have one or more plexiform neurofibromas, which are formed during embryologic development [5]. The molecular basis of MPNSTs has been linked to mutations in the $N F 1$ gene at $17 \mathrm{q} 11.2$, and its encoded tumor suppressor, neurofibromin [6], which has a GTPase-activating protein-related domain (GRD) with homology to the RAS-GTPase. This domain binds to the RAS protein and hydrolyzes GTP-bound active RAS to its inactive GDP-bound form [7]. Hence, loss of both NF1 alleles results in aberrant hyperactivation of RAS signaling, leading to dysregulation of cell growth, differentiation and survival, and predisposes NF1 patients to a variety of benign and malignant tumors, including MPNSTs [8].

Loss of NF1 appears to be a primary driver of MPNST pathogenesis, and this gene is frequently inactivated somatically in sporadic MPNSTs [9]. Since RAS is hyperactivated due to NF1 loss, studies to identify drugs that may be useful against MPNSTs have focused on inhibitors of RAS downstream signaling pathways, including MEK, AKT, and mTOR, with variable results [10-15]. Thus, unresectable MPNSTs remain largely refractory and are a major cause of 
death in NF1 patients. Twenty-six percent of deaths among patients with NF1 are caused by MPNSTs, and $60 \%$ of these deaths occur in patients under 40 years of age $[16,17]$. Currently, surgical excision is the only curative therapy, but many patients have multifocal, unresectable or metastatic tumors at diagnosis, and the recurrence rate after surgery is high $[18,19]$. Chemotherapy regimens, although partially effective in some cases, typically produce significant toxicities that can severely limit the patients' quality of life.

We have generated an $n f 1$ mutant zebrafish model and shown that the combination of $n f l$ loss and tp53 deficiency promotes a higher penetrance and much more rapid onset of MPNSTs than is observed in the absence of $n f l$ alone $[20,21]$. Brohl et al. [22] reported the results of nextgeneration sequencing of MPNSTs combined with a literature survey of $>64$ human MPNST tumor samples. In that study, mutation frequencies of NFI and TP53 were $87.5 \%$ and $40.3 \%$, respectively, indicating the relevance of our zebrafish model with $N F 1$ - and tp53-inactivating mutations [22]. Moreover, the histologic features of the MPNSTs in zebrafish are very similar to those of the human tumors $[15,20]$. To optimize this model for in vivo imaging, we bred the fish to a stable transgenic line expressing $m$ Cherry, controlled by the zebrafish sox10 neural crestspecific promoter, resulting in fluorescent labeling of MPNST tumors in living zebrafish [15]. The labeled tumor cells were then implanted into the pericardial cavity of 2 day-old pigmentless Casper recipient embryos, as a means to assess promising drugs and drug combinations against MPNST cells in vivo.

Here, we identify DNA topoisomerase I-targeted drugs as potent inducers of MPNST cell death. Moreover, two topoisomerase I poisons, topotecan or irinotecan, acted synergistically with either of two mTOR kinase inhibitors, AZD2014 or INK128, to induce tumor cell death without undue toxicity to the host. We show that the mechanisms underlying the synergy between these drugs center around the markedly enhanced inhibition of 4E-BP1 phosphorylation induced by the combination. This results in the lack of free eIF4E and an arrest of $5^{\prime}$ cap-dependent protein synthesis, which promotes tumor cell apoptosis. These data provide a compelling further in vivo testing of DNA topoisomerase I-targeted drugs in combination with mTOR kinase inhibitors against MPNSTs.

\section{Results}

\section{Pericardial injection of mCherry-labeled zebrafish MPNST cells generates a rapidly growing tumor cell mass for drug testing}

We have developed an embryonic implantation assay using zebrafish mCherry-labeled MPNST cells to generate large numbers of uniformly injected embryos for assessment of the activity of drugs added to fish water in 96-well plates. In this assay, primary zebrafish MPNST tumor cells are harvested from an $n f l a+/-; n f l b-/-; p 53 \mathrm{~m} / \mathrm{m}$; sox 10 : $m$ Cherry zebrafish line, and microinjected into the pericardial cavity of pigmentless Casper recipient zebrafish embryos at 2 days post fertilization (dpf) (Fig. 1). This technique provides a uniform mass of tumor cells that can be readily visualized by fluorescence stereomicroscopy at $24 \mathrm{~h}$ after injection, in an anatomic region of the fish that is free of autofluorescence and other background signals (Fig. 1a) and is a reported site of both primary and metastatic human MPNSTs [23, 24]. After injection into the pericardial cavity, the tumor cells grow rapidly, forming a spherical mass of tumor cells, such that the cross-sectional area increases $\sim 10$-fold over 6 days (Fig. 1b). Thus, our assay provides a reproducible and quantifiable mass of MPNST cells growing in vivo for assessment of the antitumor activity and toxicity of small-molecule drugs.

\section{DNA topoisomerase I-targeted drugs show potent activity against zebrafish MPNSTs in the embryonic pericardial implantation assay}

Genetic defects in MPNST cells profoundly affect growth signaling, including the activities of the PI3K-AKT-mTOR, RAS-ERK, and Wnt pathways [21]. Thus, we evaluated a series of compounds with recognized or potential value as inhibitors of selected signaling pathways, using the embryonic implantation assay. The maximum-tolerated dose (MTD) was determined for each drug or drug combination in 3- to 7-day-old Casper embryos. This measure was defined as the maximum concentration of drug in the fish water allowing at least seven of the nine treated embryos (not implanted with tumor cells) to survive without apparent abnormalities for the 4-day treatment period (from 3 to $7 \mathrm{dpf}$ ) and to remain alive without apparent abnormalities for at least an additional 7 days after drug removal. We then injected MPNST cells harvested from nfla $+/-$; nflb-/-; p53-/-; sox10:mCherry zebrafish into the pericardial cavity of 2-day-old Casper embryos. After $24 \mathrm{~h}$, successfully implanted embryos were imaged, distributed one embryo per well into 96-well plates, and incubated with each test drug for 4 days at the MTD or with the DMSO vehicle control. Drug activity against MPNST cells was determined at $7 \mathrm{dpf}$ by comparing images obtained before and after drug treatment (see Fig. 2a for details).

Of 11 compounds tested in embryos implanted with MPNST cells (Fig. 2b), four demonstrated significant activity against MPNST cells, based on decreases in the red fluorescent area of the pericardial cavity: PD-0325901 (MEK inhibitor, 50 nM), AZD2014 (mTOR kinase inhibitor, $30 \mu \mathrm{M}$ ), KPT-330 (XPO1 inhibitor, $2 \mu \mathrm{M}$ ) and 
a
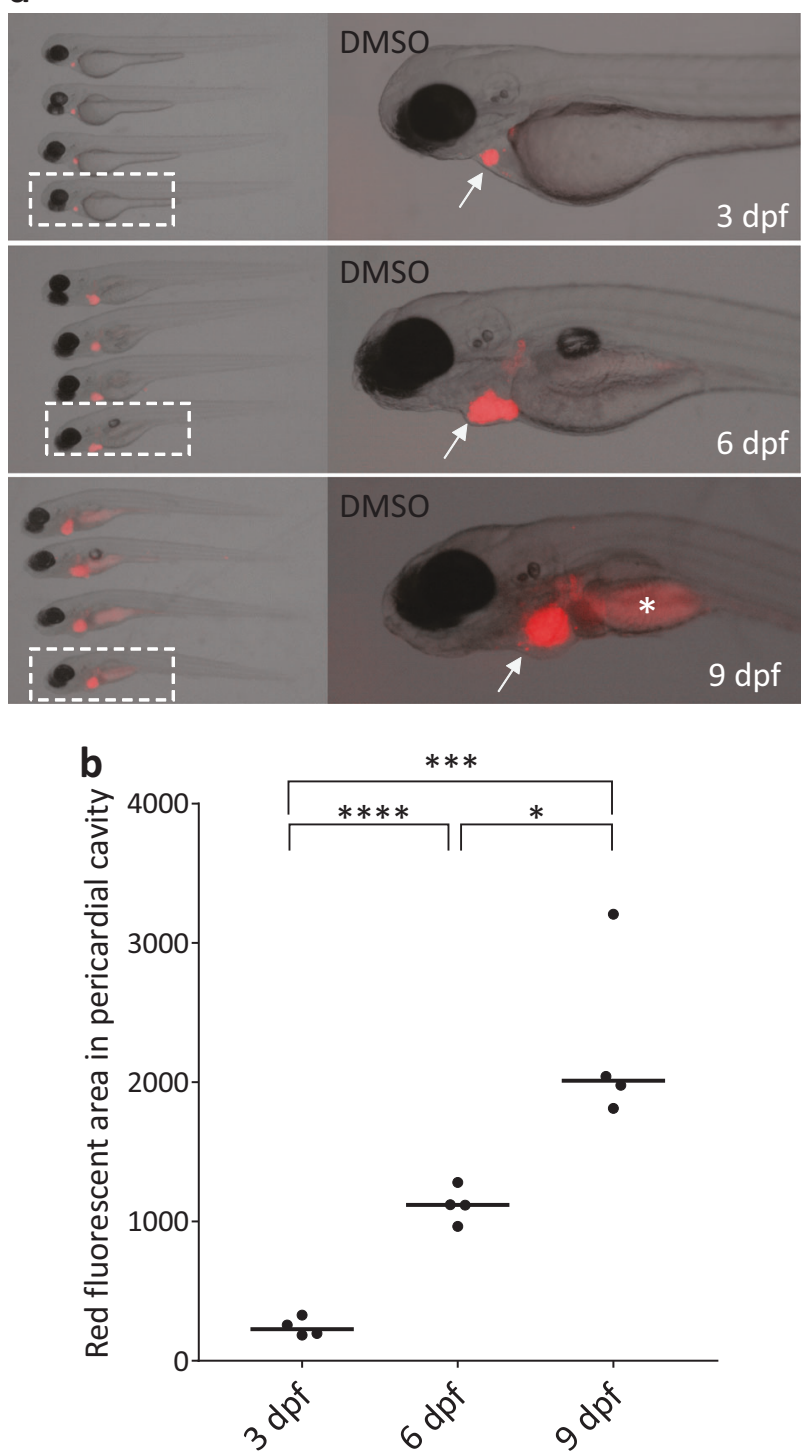

Fig. 1 Implanted malignant peripheral nerve sheath tumor (MPNST) cells form quantifiable mass in the pericardial cavity of zebrafish embryos. a Injected mCherry-labeled primary MPNST cells expand under dimethyl sulfoxide (DMSO) treatment in vivo. Right panels show enlarged views to areas outlined by white boxes (left). White arrows indicate injected tumor cells; the asterisk denotes autofluorescence from gut. b Quantification of implanted tumor cell growth. Each dot represents a cross-sectional red fluorescent area (pixel) of each embryo; bars indicate median values. $* p=0.013$, *** $p$ $=0.0008, * * * p<0.0001(n=4$, Student's $t$-test $)$

topotecan (DNA topoisomerase I-targeted drug, $5 \mu \mathrm{M}$ ). Treatment with these compounds resulted in less growth over 4 days than observed for the dimethyl sulfoxide (DMSO)-treated embryos. The strongest responses were elicited by topotecan (Fig. 2b, c), which was the only compound to significantly reduce the area of red fluorescence. While the fluorescent cross-sectional area of the control cells expanded 4.6-fold (2.26 $\log 2$ ratio) over 4 days, topotecan treatment induced a 2.5 -fold decrease by comparison with the day-3 $(-1.31 \log 2$ ratio) result (Fig. 2b). Drug-treated embryos did not show any discernible morphologic defects, and their movements were similar to those of control embryos, suggesting only limited toxicities.

Given this response to topotecan, we also tested the related DNA topoisomerase I-targeted drug irinotecan. Irinotecan similarly inhibited tumor growth compared to controls in a dose-dependent manner (Fig. 2d). Next, to assess the durability of the drug response, we transferred drug-treated embryos into fresh water at $7 \mathrm{dpf}$ and observed them for MPNST cell expansion. While DMSO-treated $m$ Cherry-expressing tumor cells gradually expanded, tumor growth in irinotecan-treated zebrafish remained unchanged for up to 7 days (from 7 to $14 \mathrm{dpf}$ ) after a 4-day irinotecan pulse (Fig. 2e, f), consistent with results obtained with topotecan (Supplementary Fig. 1). These data demonstrate the utility of DNA topoisomerase I-targeted drugs in this model and suggest that they may be useful agents for the treatment of MPNST.

\section{DNA topoisomerase l-targeted drugs and mTOR inhibitors synergistically kill MPNST cells in vivo}

To identify agents that might potentiate the activity of DNA topoisomerase I-targeted drugs in MPNST therapy, we first combined either irinotecan or topotecan with other targeted agents, including the MEK inhibitors selumetinib and trametinib, the mTOR complex 1 (mTORC1) inhibitors rapamycin and everolimus, the ATP-competitive mTOR kinase inhibitors AZD2014 and INK128 or the PARP inhibitors veliparib and talazoparib. We also decreased the irinotecan dose to $1.5 \mu \mathrm{M}$ for minimal drug activity and tested each drug combination for its MTD after this reduction in the zebrafish embryonic implantation assay. Identical results were obtained when the same drugs were combined with topotecan or irinotecan, so for simplicity, only data for the latter compound are shown in Fig. 3. In contrast to most agents, we noted significant enhancement of irinotecan activity with use of the mTOR kinase inhibitors AZD2014 and INK128 (Fig. 3a, b). Given alone at these dosages, irinotecan, AZD2014, and INK128 resulted in only minimal decreases in the fluorescent tumor area compared to controls. Intriguingly, irinotecan combined with AZD2014 or INK128 led to the most striking tumor responses. After 4 days of drug treatment $(7 \mathrm{dpf})$, we transferred the embryos to fresh water to observe tumor growth (Fig. 3c). The implanted MPNST cells in the DMSO-, irinotecan-, AZD2014-, and INK128-only groups immediately began to regrow in the absence of drug, whereas the tumor cells treated with irinotecan and either 


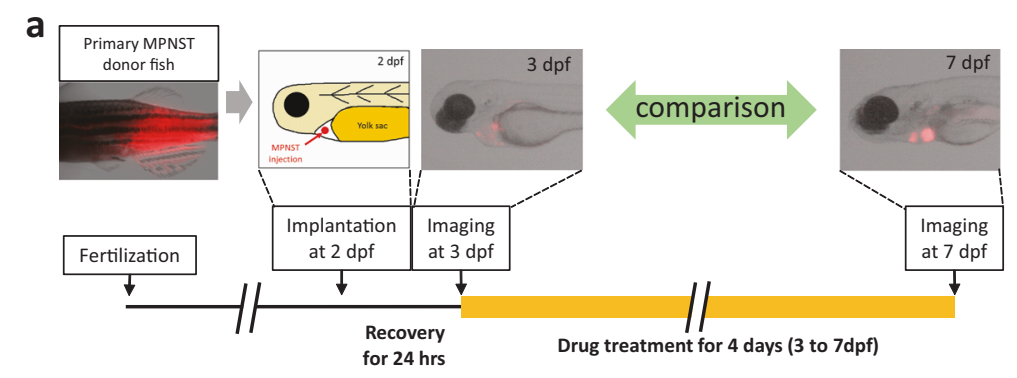

b

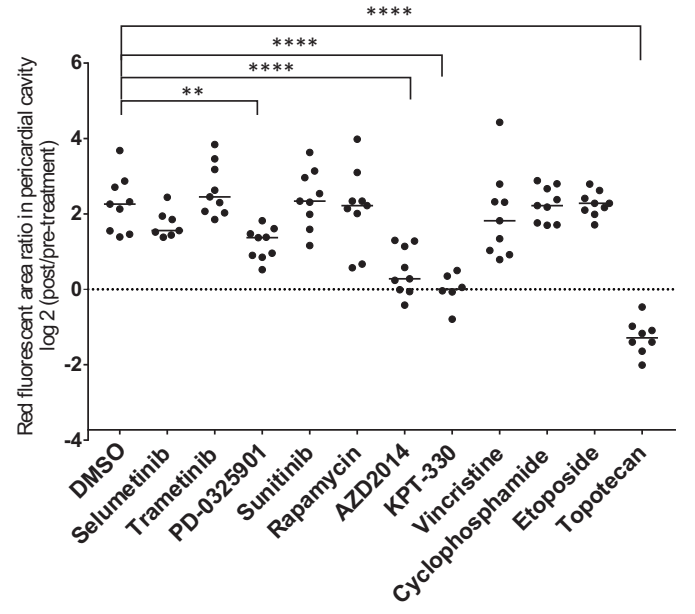

d

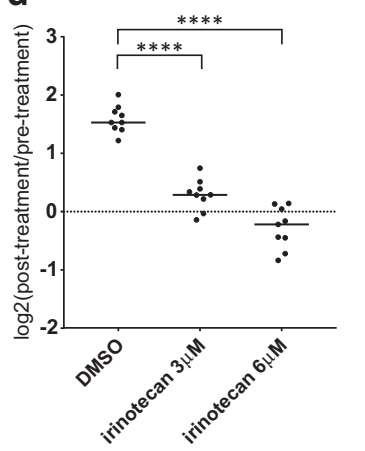

e

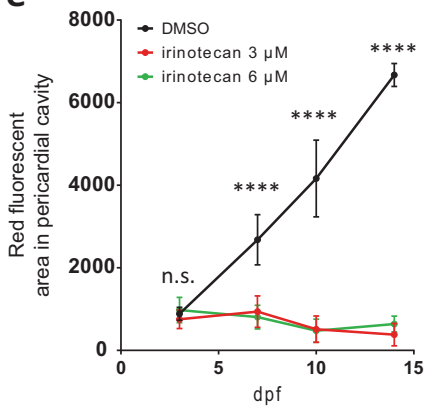

Fig. 2 DNA topoisomerase I-targeted drugs show potent activity against malignant peripheral nerve sheath tumor (MPNST). a Schematic diagram of the implantation and drug treatment assay. Primary zebrafish MPNST cells were transplanted into 2-dpf embryos and treated with drugs in the fish water from 3 to $7 \mathrm{dpf}$. Drug activity was determined by decreases in tumor growth (mCherry-positive area of the pericardial cavity) after 4 days of treatment. b MPNST tumor cell growth in the pericardial cavity of implanted embryos. These embryos were treated with dimethyl sulfoxide (DMSO) vehicle control, selumetinib $(50 \mu \mathrm{M})$, trametinib (100 nM), PD-3025901 (50 nM), sunitinib $(4 \mu \mathrm{M})$, rapamycin $(5 \mu \mathrm{M})$, AZD2014 $(30 \mu \mathrm{M})$, KPT-330 $(2 \mu \mathrm{M})$, vincristine $(50 \mu \mathrm{M})$, cyclophosphamide $(100 \mu \mathrm{M})$, etoposide $(100 \mu \mathrm{M})$, or topotecan $(5 \mu \mathrm{M})(n=9$ fish per treatment, doses based on the MTD of the individual drug). The fluorescent tumor area was determined for each embryo at $3 \mathrm{dpf}$ (pre-treatment) and $7 \mathrm{dpf}$ (post treatment), and was reported as the median ratio (range) of the red fluorescent area at 3

AZD2014 or INK128 showed a sustained response and demonstrated no growth at all after the embryos had been in fresh water for a week (14 dpf, Fig. 3c).
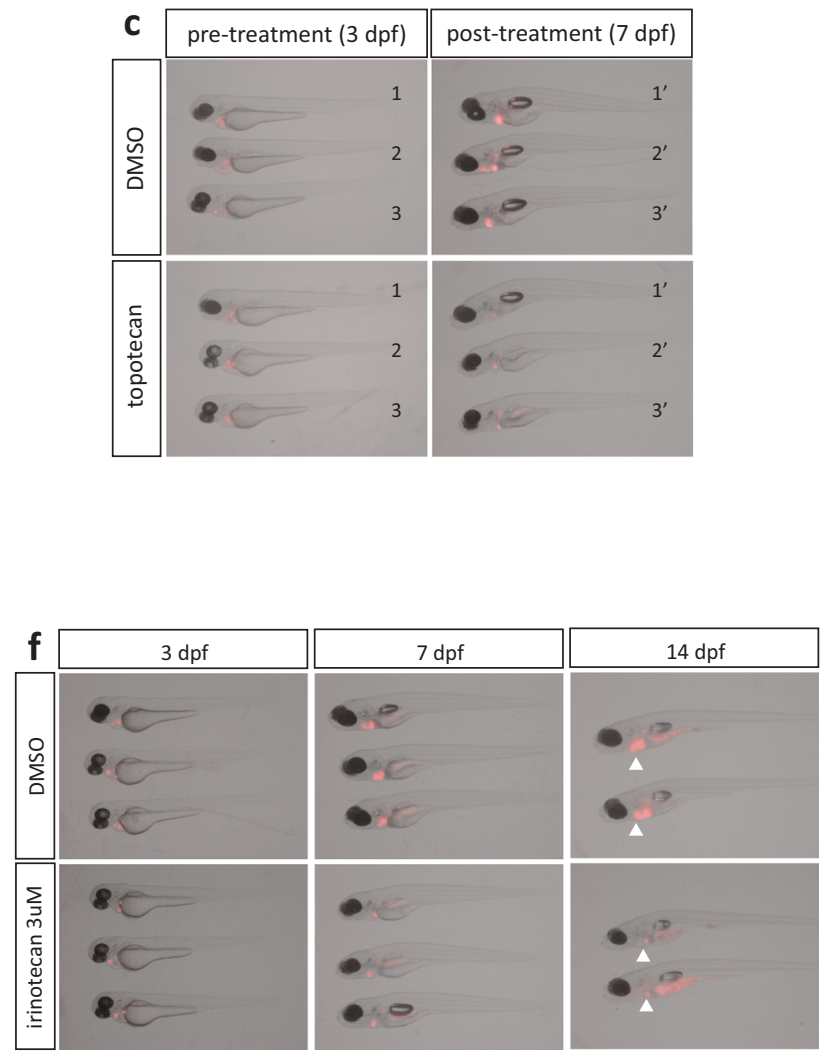

vs. $7 \mathrm{dpf}$ in individual embryos. $* * p=0.0021$, $* * * *<0.0001$ by Student's $t$-test. c Representative fish images at $3 \mathrm{dpf}$ and $7 \mathrm{dpf}$ after DMSO control or topotecan treatment. The embryos in each DMSO or topotecan panel are identical. d MPNST cell growth in the pericardial cavity after treatment with $3 \mu \mathrm{M}$ or $6 \mu \mathrm{M}$ of irinotecan or DMSO control. Tumor growth is reported as the median ratio (range) of the mCherry expression area of individual embryos at before $(3 \mathrm{dpf})$ and after ( $7 \mathrm{dpf}$ ) treatment ( $n=9$ embryos per group). e Duration of MPNST cell growth inhibition after 4 days of drug treatment. Growth measurements at $3,7,10$, and $14 \mathrm{dpf}$ were based on red fluorescence areas of the pericardial cavity, and are reported as mean \pm SD values. $* * * * p<0.0001$ in panels $\mathbf{d}$ and e (Student's $t$-test); n.s., not significant. f Representative fish images at 3, 7, and $14 \mathrm{dpf}$ after DMSO control and $3 \mu \mathrm{M}$ of irinotecan treatment. White arrowheads indicate tumor cells remaining in the pericardial cavity

We also tested the effects of the irinotecan plus AZD2014 combination on nontransformed cells transplanted into the pericardial cavity. In this experiment, we 


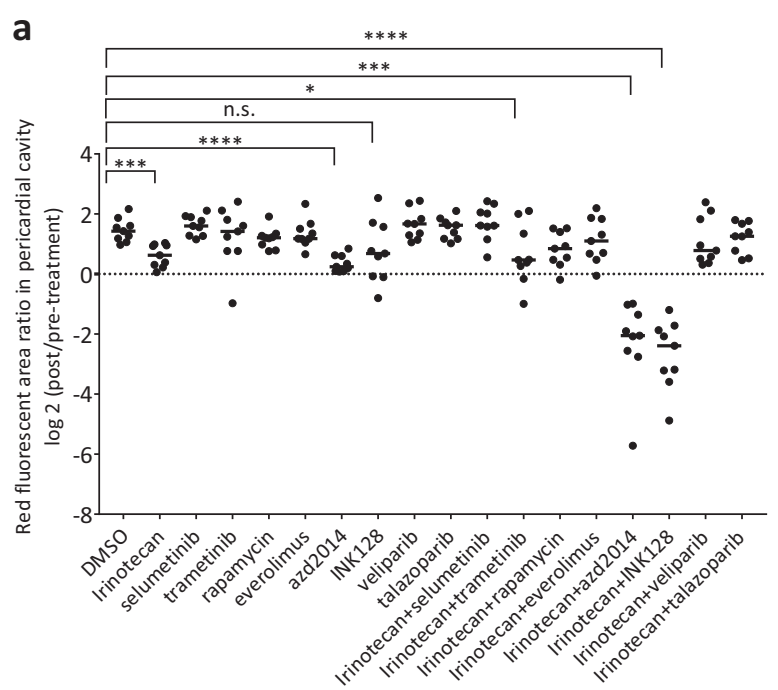

Fig. 3 Activity of irinotecan is enhanced by AZD2014 and INK128 in the embryonic implantation assay. a Malignant peripheral nerve sheath tumor (MPNST) cell growth in the pericardial cavity after 4 days of treatment with irinotecan combined with MEK, mTOR, mTORC1/2, or PARP inhibitors. The embryos were also treated with vehicle control, irinotecan $(1.5 \mu \mathrm{M})$, selumetinib $(12.5 \mu \mathrm{M})$, trametinib $(100 \mathrm{nM})$, rapamycin $(1 \mu \mathrm{M})$, everolimus $(1 \mu \mathrm{M})$, AZD2014 $(20 \mu \mathrm{M})$, INK128 $(1 \mu \mathrm{M})$, veliparib $(1.25 \mu \mathrm{M})$, and talazoparib $(50 \mathrm{nM})$ as single

harvested nontransformed cells from 1-year-old wild-type zebrafish harboring the ubi:GFP fluorescent marker, mechanically dissociated them into a single-cell preparation and transplanted 100-120 cells into recipient Casper embryos. After injection, the cross-sectional area occupied by the nontransformed, GFP-labeled cells did not change significantly from $3 \mathrm{dpf}$ to $7 \mathrm{dpf}$, indicating that the cells survived but on average did not increase in numbers. When irinotecan $(1.5 \mu \mathrm{M})$ and AZD2014 $(20 \mu \mathrm{M})$ were added to the fish water, the transplanted-cell area of GFP fluorescence did not decrease significantly over this interval (Supplementary Fig. 2). Thus, in contrast to transformed MPNST cells, the transplanted nontransformed cells survived but did not grow or respond appreciably to treatment with these drugs. These preclinical results indicate that combined inhibition of topoisomerase I and mTOR kinase with tolerable dosages of the drugs tested here may provide an effective therapeutic strategy against human MPNSTs.

\section{Irinotecan acts synergistically with INK128 to kill human MPNST cells}

To evaluate the relevance of DNA topoisomerase I-targeted drugs in human MPNST cells, we tested the effect of irinotecan on the growth of multiple human MPNST cell lines. This agent was active in two NF1 mutant (sNF96.2
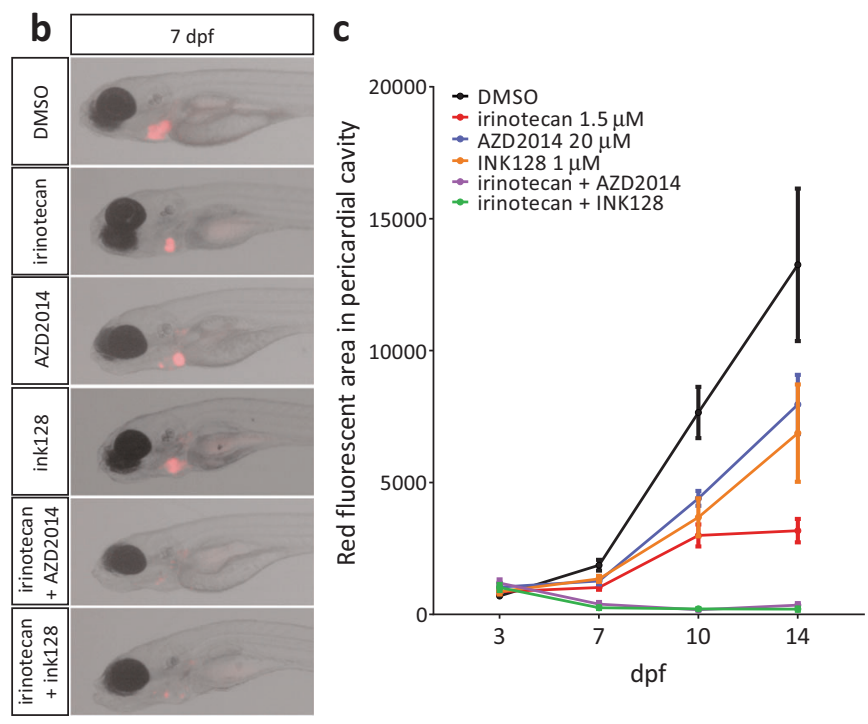

agents ( $n=9$ embryos per treatment). Individual values with medians (black bars) are shown. $* p<0.05, * * * p<0.001, * * * p<0.0001$ (Student's $t$-test); n.s. $=$ not significant. b Representative embryo images after embryonic implantation assay at $7 \mathrm{dpf}$. c Implanted tumor cell growth in pericardial cavity. Red fluorescent areas (pixel) were measured at 3, 7, 10, and $14 \mathrm{dpf}$; results are reported as means \pm SEM of red fluorescent areas in the pericardial cavity

and ST8814) cell lines and one NF1 wild-type (STS26T) MPNST line, with $\mathrm{IC}_{50}$ values of irinotecan ranging from 340 to $932 \mathrm{nM}$ at $72 \mathrm{~h}$ of drug exposure (Fig. 4a). Similar results were obtained with topotecan $\left(\mathrm{IC}_{50}\right.$ range, 63.4 to $301 \mathrm{nM}$ ) (Supplementary Fig. 3). In tests of mTOR kinase inhibitors in human MPNST cells, we treated the sNF96.2, ST8814, and STS26T cell lines with INK128, which showed some activity against each line $\left(\mathrm{IC}_{50}\right.$ values at $72 \mathrm{~h}$ of treatment, $46.27 \mathrm{nM}$ for sNF96.2; $161.9 \mathrm{nM}$ for ST8814; and $226.1 \mathrm{nM}$ for STS26T) (Fig. 4b). These results agree with those previously reported for the mTOR kinase inhibitor AZD8055, a close analog of AZD2014 [13]. By contrast, the mTORC1 inhibitor rapamycin did not decrease MPNST cell numbers in a dose-dependent manner (Supplementary Fig. 3c; also ref. [13]), indicating that direct mTOR kinase inhibitors had more profound effects on MPNST cell numbers than did rapamycin.

Since AZD2014 and INK128 enhanced irinotecan drug activity in the embryonic implantation assay (Fig. 3), we next evaluated this property in human MPNST cells, using isobologram analysis to establish whether this inhibitor acts synergistically with irinotecan against MPNST cells (Fig. 4c-h). Both the sNF96.2 and ST8814 MPNST cell lines are NF1 null and TP53 wild-type, while the STS26T line is NF1 wild-type and TP53 null. Each cell line was cultured for $72 \mathrm{~h}$ with different concentrations of irinotecan and INK128, both alone and in combination (Fig. $4 \mathrm{c}, \mathrm{e}, \mathrm{g}$ ). The combination 

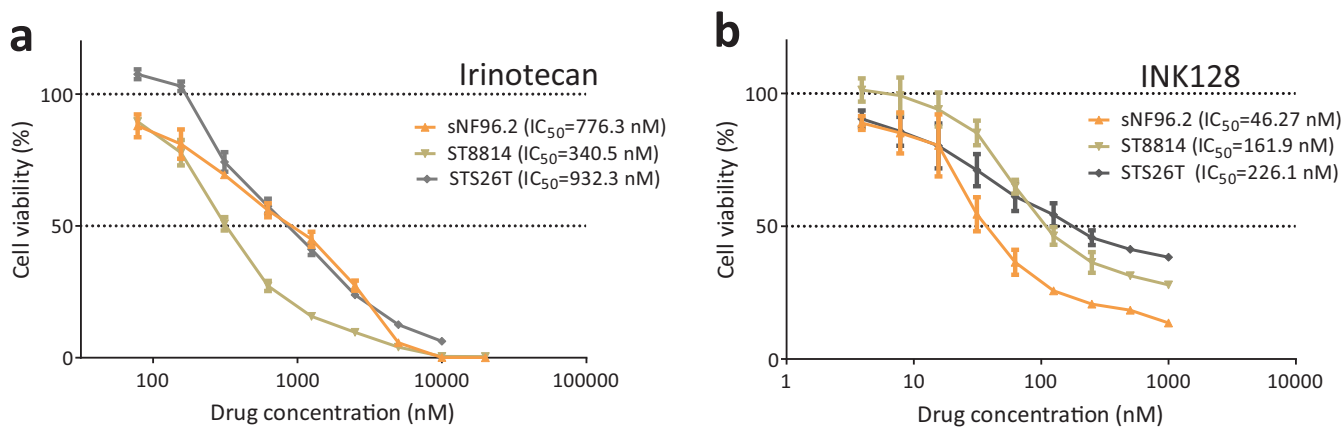

\begin{tabular}{cccc}
$\begin{array}{c}\text { color } \\
\text { code }\end{array}$ & $\begin{array}{c}\text { Irinotecan } \\
\text { (nM) }\end{array}$ & $\begin{array}{c}\text { INK128 } \\
\text { (nM) }\end{array}$ & $\begin{array}{c}\text { combination } \\
\text { index }\end{array}$ \\
\hline \hline & 250 & 20 & 0.51 \\
& 250 & 30 & 0.52 \\
& 250 & 40 & 0.50 \\
& 500 & 20 & 0.74 \\
& 500 & 30 & 0.67 \\
& 500 & 40 & 0.64 \\
& 750 & 20 & 0.94 \\
& 750 & 30 & 0.87 \\
750 & 40 & 0.83
\end{tabular}

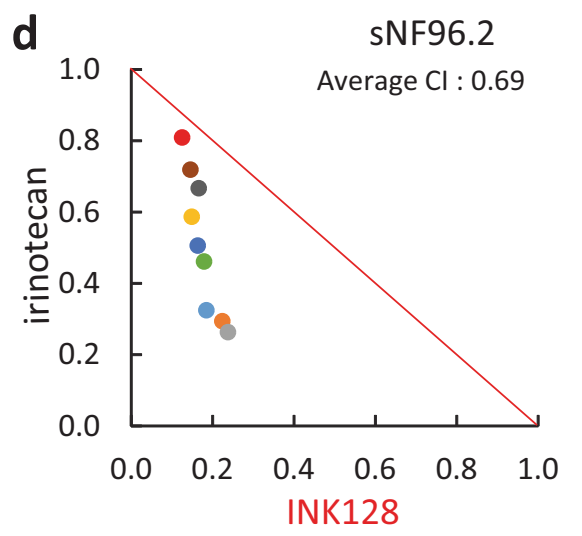

\begin{tabular}{cccc}
$\begin{array}{c}\text { Color } \\
\text { code }\end{array}$ & $\begin{array}{c}\text { Irinotecan } \\
(\mathrm{nM})\end{array}$ & $\begin{array}{c}\text { INK128 } \\
\text { (nM) }\end{array}$ & $\begin{array}{c}\text { combination } \\
\text { index }\end{array}$ \\
\hline \hline & 250 & 90 & 0.53 \\
& 250 & 120 & 0.50 \\
& 250 & 150 & 0.46 \\
& 300 & 90 & 0.56 \\
& 300 & 120 & 0.51 \\
& 300 & 150 & 0.47 \\
& 350 & 90 & 0.55 \\
& 350 & 120 & 0.50 \\
350 & 150 & 0.51
\end{tabular}

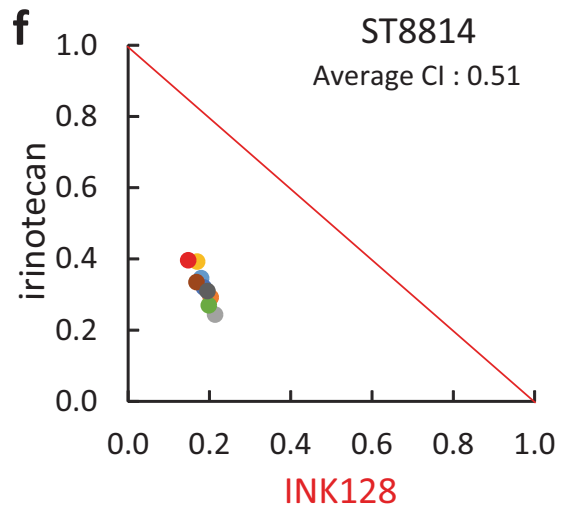

\begin{tabular}{cccc}
\hline $\begin{array}{c}\text { color } \\
\text { code }\end{array}$ & $\begin{array}{c}\text { Irinotecan } \\
(\mathrm{nM})\end{array}$ & $\begin{array}{c}\text { INK128 } \\
(\mathrm{nM})\end{array}$ & $\begin{array}{c}\text { combination } \\
\text { index }\end{array}$ \\
\hline \hline & 500 & 100 & 0.20 \\
& 500 & 150 & 0.23 \\
& 500 & 300 & 0.34 \\
& 700 & 100 & 0.24 \\
700 & 150 & 0.27 \\
700 & 300 & 0.28 \\
900 & 100 & 0.28 \\
& 900 & 150 & 0.29 \\
900 & 300 & 0.27
\end{tabular}

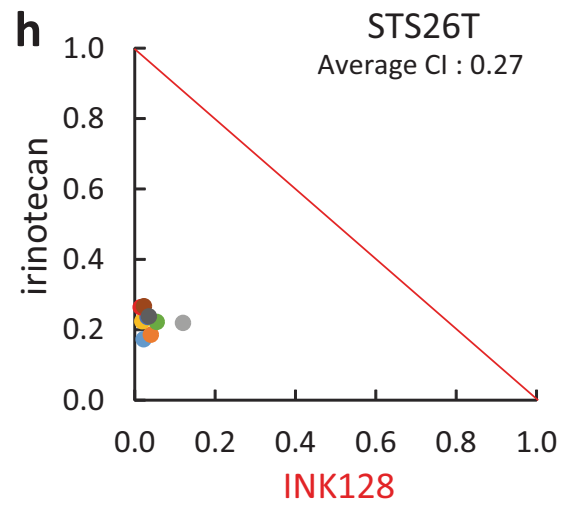

index values for each irinotecan and INK128 drug pair were $<1.0$, indicating that when used together these drugs are synergistic against sNF96.2, ST8814, and STS26T cells

(Fig. 4d, f, h). We conclude that mTOR kinase inhibitors act synergistically with DNA topoisomerase I-targeted drugs against human MPNST cells. 
Fig. 4 Irinotecan shows synergistic activity with INK128 against human malignant peripheral nerve sheath tumor (MPNST) cell lines. a, b Single-drug treatment of human MPNST cell lines with irinotecan or INK128. sNF96.2, ST8814, and STS26T cells were cultured with increasing concentrations of irinotecan (a) or INK128 (b) for $72 \mathrm{~h}$. Cell viability values were determined as mean \pm SD percentages of the untreated control value in triplicate experiments. The $\mathrm{IC}_{50}$ values of each cell line in this assay are indicated in parentheses. $\mathbf{c}-\mathbf{h}$ Normalized isobologram (obtained with Calcusyn software) over a range of irinotecan and INK128 dosage combinations. sNF96.2 cells were cultured with the irinotecan and INK128 combination represented in panel c, and their growth was measured at $72 \mathrm{~h}$. The combination index (CI) was plotted as a function of dose combination, with average CIs for the drug combination reported in panel $\mathbf{d}$. The additive isobole is depicted in this panel as a red straight line, with synergistic dose combinations labeled below the isobole. An average CI of 1 indicates an additive effect, $\mathrm{CI}<1$ a synergistic effect, and $\mathrm{CI}>1$ an antagonistic effect. Experiments performed in panels $\mathbf{c}$ and $\mathbf{d}$ were repeated with ST8814 (e, f) and STS26T $(\mathbf{g}, \mathbf{h})$ cells

\section{Irinotecan plus INK128 induces apoptotic cell death in human MPNST cells}

The combination of irinotecan and INK128 exhibited synergistic activity against MPNST cells by isobologram analysis (Fig. 4). To confirm this result, we studied the growth kinetics of sNF96.2, ST8814, and STS26T cells over 4 days with relatively low dosages of irinotecan and INK128 alone and in combination, such that the drugs contributed approximately equal antitumor cell potency (Fig. 5a-c). While single agents produced slight reductions in cell growth, treatment with the combination was highly cytotoxic to the tumor cells, leading to substantial decreases in cell number. This treatment strategy was less effective when rapamycin was substituted for the mTOR kinase inhibitors (Supplementary Fig. 4). We next asked if the observed effects of the combination treatment would result in apoptosis in human MPNST cell lines. In this experiment, we performed an Annexin $\mathrm{V}$ and propidium iodide (PI) staining assay with sNF96.2, ST8814, and STS27T cells after 48 to $72 \mathrm{~h}$ of exposure to irinotecan and INK128, both alone and in combination (Fig. 5d-g). Flow cytometry results indicated that the apoptosis rate in the drug combination-treated cells (early + late apoptosis rate) was higher than that in the single-drug-treated cells. Indeed, although the apoptosis rate among INK128-treated cells was similar to or lower than that of DMSO controls, it was significantly increased among cells treated with the combination of irinotecan and INK128. Comparable results were obtained with the combination of irinotecan and AZD2014 (Supplementary Fig. 5a-c). We also performed a TUNEL assay with SNF96.2 and ST8814 cells after $24 \mathrm{~h}$ of drug exposure, observing a marked increase in the fraction of cells undergoing apoptosis in MPNST cells treated with irinotecan plus AZD2014, as compared to cells exposed to either irinotecan or AZD2014 alone (Supplementary Fig. 5d).
A combination of irinotecan and AZD2014 prevents 4E-BP1 phosphorylation and blocks protein synthesis

Although the combination of DNA topoisomerase I-targeted drugs and mTOR kinase inhibitors clearly produced synergistic activity against MPNST cells, the molecular mechanism for this effect was unclear. Thus, we first asked whether AZD2014 could potentiate the DNA damage response known to be elicited by DNA topoisomerase Itargeted drugs like irinotecan. Topoisomerase I cleaves one strand of double-stranded DNA to form transient intermediates that relax super-coiled DNA as an early step in transcription or replication [25]. DNA topoisomerase I poisons act by stabilizing topoisomerase I-DNA intermediates, such that double-stranded DNA breaks occur during replication with an accompanying DNA damage response that induces cell cycle arrest and apoptosis $[26,27]$. To address whether inhibition of mTOR potentiates the DNA damage response induced by DNA topoisomerase I-targeted drugs, we first analyzed the extent of phosphorylation of $\mathrm{H} 2 \mathrm{AX}(\gamma \mathrm{H} 2 \mathrm{AX})$ in response to treatment with these drugs. Potent induction of $\gamma \mathrm{H} 2 \mathrm{AX}$ after treatment of MPNST cells with irinotecan was evident by $24 \mathrm{~h}$ in sNF96.2 cells and $48 \mathrm{~h}$ in ST8814 cells, as expected (Supplementary Fig. 6). The level of $\gamma \mathrm{H} 2 \mathrm{AX}$ was not affected by treatment with AZD2014 alone or in combination, indicating that mTOR inhibition does not synergize with DNA topoisomerase I-targeted drugs by augmenting the DNA damage response.

Subsequently, we considered phosphorylation of key downstream targets of mTORC1 as a putative mechanistic driver, including the ribosomal protein S6 kinase (p70S6K) as well as 4E-BP1, which binds the eukaryotic translation initiation factor 4E (eIF4E). As shown in Fig. 6a, treatment with AZD2014 for $24 \mathrm{~h}$ (lane A) reduced the phosphorylation levels of both p70S6K and 4E-BP1 in MPNST cells. We also tested whether irinotecan affects the phosphorylation of these key downstream targets of mTORC1 (lane I), observing that treatment with this agent alone mediates a small but measurable reduction in the phosphorylation levels of both 4E-BP1 and p70S6K (Fig. 6a). These findings are consistent with published results showing reduced phosphorylation levels of both targets in mouse fibroblasts and various types of human cancer cells in response to DNA damage [28, 29]. To directly address the issue of synergism, we used irinotecan and AZD2014 together and showed that the combination strongly suppressed the phosphorylation of 4E-BP1 (Ser65) at $24 \mathrm{~h}$ in both sNF96.2 and ST8814 cells (Fig. 6a), and in TP53 mutant S462 human MPNST (NF1 null, SUZ12 null, and TP53 mutant) cells (Supplementary Fig. 7). In these experiments, the three different forms of phosphorylated 4EBP1 protein $(\alpha, \beta$, and $\gamma)$ are evident by western blotting. The $\alpha$-band represents the unphosphorylated form and the $\gamma$-band 

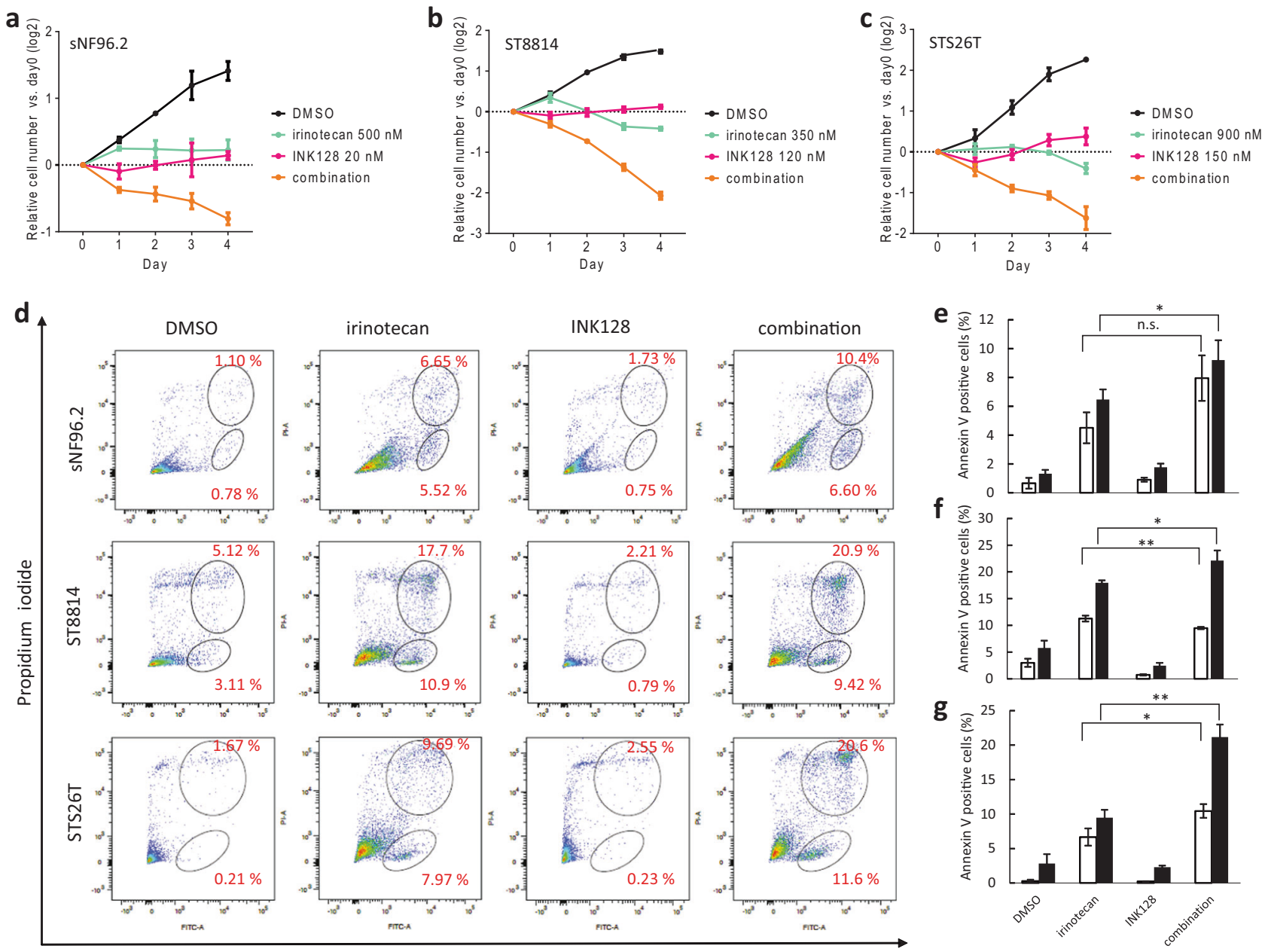

Annexin V-FITC

Fig. 5 Irinotecan plus INK128 induces apoptotic cell death in human malignant peripheral nerve sheath tumor (MPNST) cell lines. a sNF96.2 cells were cultured with $500 \mathrm{nM}$ of irinotecan, $20 \mathrm{nM}$ of INK128, a combination of irinotecan and INK128, or dimethyl sulfoxide (DMSO), and their viability was measured. Values are mean \pm $\mathrm{SD}$ fold changes relative to the measurement on day 0 in three independent biological experiments. b, $\mathbf{c}$ Experiment performed in panel a was repeated with ST8814 (b) or STS26T (c) cells. ST8814 cells were cultured with $350 \mathrm{nM}$ of irinotecan, $120 \mathrm{nM}$ of INK128 or a combination of irinotecan and INK128 or DMSO, while STS26T cells were cultured with $900 \mathrm{nM}$ of irinotecan, $150 \mathrm{nM}$ of INK128 or a combination of irinotecan and INK128 or DMSO. d Apoptotic sNF96.2,

the most highly phosphorylated form of the protein. The highly phosphorylated $\gamma$-form of 4E-BP1 was most strongly downregulated in both cell lines by the combination of irinotecan and AZD2014 (Fig. 5). The phosphorylation of p70S6K (Thr389) was decreased by AZD2014 and the combination of irinotecan and AZD2014; however, rapamycin inhibited p70S6K phosphorylation even more strongly despite its failure to inhibit 4E-BP1 phosphorylation, consistent with its known specificity for the mTORC1 kinase activity of p70S6K and its lack of activity against 4E-BP1 phosphorylation [30, 31].
ST8814, or STS26T cells detected with Annexin V-FITC/propidium iodide (PI) staining, and analyzed by flow cytometry. Representative flow plots are shown $(n=3)$. Each cell line was cultured for $72 \mathrm{~h}$ (sNF96.2) or $48 \mathrm{~h}$ (ST8814 and STS26T) with the concentrations of irinotecan and INK128 shown in panel $\mathbf{a}, \mathbf{b}$ or $\mathbf{c}$. $\mathbf{e}-\mathbf{g}$ Annexin-positive cells were counted in triplicate experiments with mean \pm SD percentages of positive cells reported in the graphs. The Annexin V-positive and PI-negative cells were defined as early apoptotic cells, while the Annexin V-and PI double-positive cells were defined as late apoptotic cells. ${ }^{*} p<0.05, * * p<0.01$ by Student's $t$-test; n.s. $=$ not significant

In view of these results, we asked how a synergistic inhibitory effect on 4E-BP1 phosphorylation could enhance antitumor activity. Very briefly, unphosphorylated 4E-BP1 binds and sequesters the translation initiation factor eIF4E, blocking $5^{\prime}$ cap-dependent translation. By contrast, when 4E-BP1 is hyperphosphorylated, it releases eIF4E, enabling it to trigger new protein synthesis [32, 33]. As irinotecan plus AZD2014 strongly suppresses the phosphorylation of 4E-BP1 (Fig. 6a), it increases the interaction between 4EBP1 and eIF4E, thus blocking 5' cap-dependent translation. The resultant robust block of new protein synthesis induced 
a

$\frac{s N F 96.2(24 h)}{\text { D I A IA R IR }} \frac{\frac{S T 8814}{(24 h)}}{\text { D I A IA R IR }}$

p-4E-BP1 (S65)

4E-BP1

p-p70S6K (T389)

p7056K

$\beta$-actin
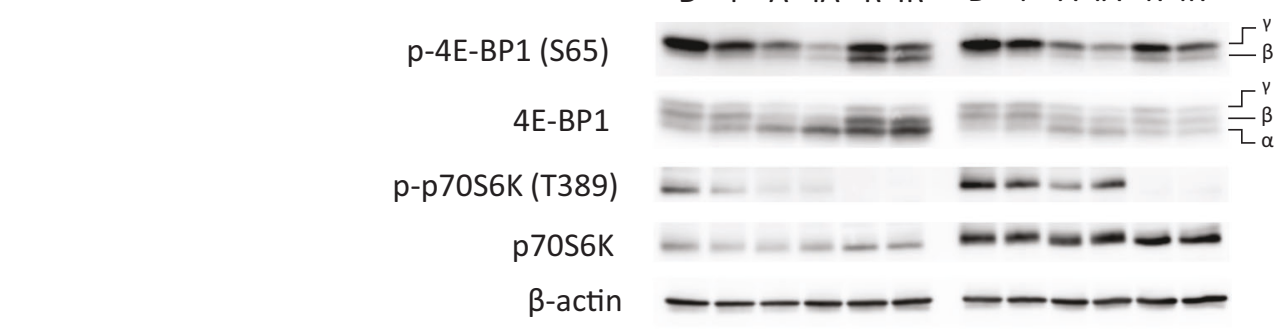

b
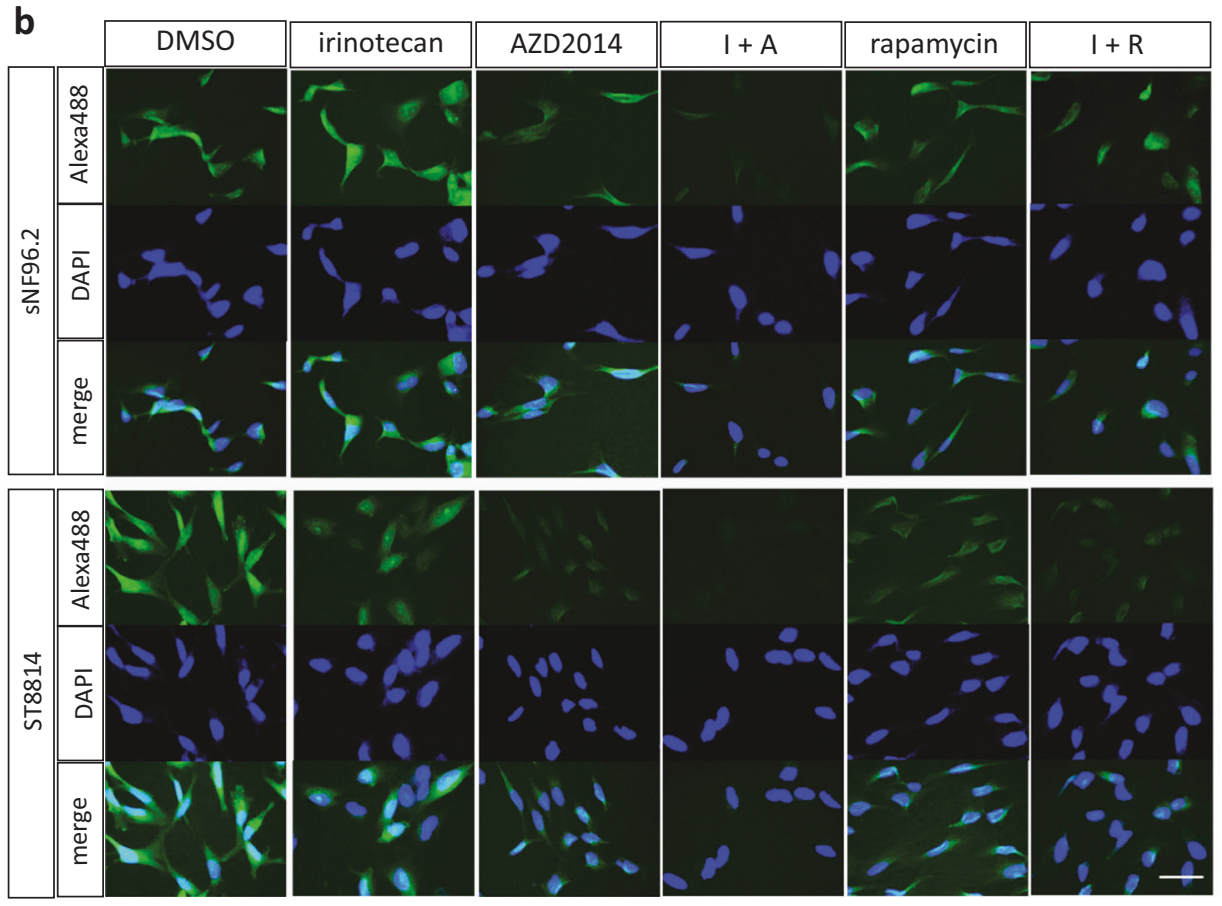
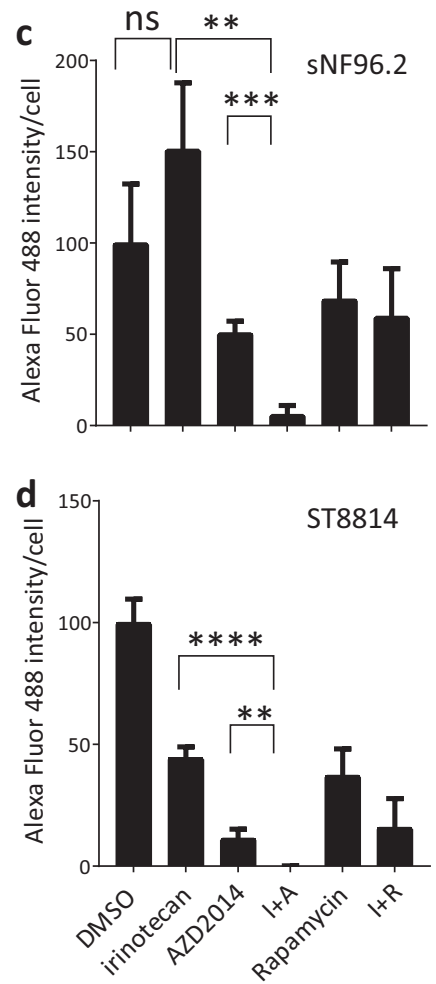

Fig. 6 Combination of irinotecan and AZD2014 prevents the phosphorylation of 4E-BP1 and inhibits nascent protein synthesis. a SNF96.2 and ST8814 cells were incubated with dimethyl sulfoxide (DMSO) (D), irinotecan (I), AZD2014 (A), a combination of irinotecan and AZD2014 (IA), rapamycin (R), or a combination of irinotecan and rapamycin (IR) for $24 \mathrm{~h}$. sNF96.2 cells were cultured with $1000 \mathrm{nM}$ of irinotecan, $200 \mathrm{nM}$ of AZD2014, $200 \mathrm{nM}$ of rapamycin or different combinations of these agents. ST8814 cells were cultured with $250 \mathrm{nM}$ of irinotecan, $400 \mathrm{nM}$ of AZD2014, $200 \mathrm{nM}$ of rapamycin or different combinations of these agents. Three different forms

by this drug combination can be seen in experiments in which L-homopropargylglycine (HPG), an amino acid analog of methionine that contains an alkyne moiety, is fed to cultured cells and incorporated into proteins during active protein synthesis (Fig. 6b). Addition of an Alexa Fluor 488 azide leads to a chemoselective "click" reaction between the fluorescent azide and the alkyne, allowing newly synthesized protein levels to be detected by fluorescence imaging. To examine the direct effects of irinotecan and AZD2014 on $5^{\prime}$ cap-dependent translation, we conducted protein of the 4E-BP1 protein $(\alpha, \beta, \gamma)$ are indicated. The $\alpha$-band represents the least phosphorylated form and the $\gamma$-band the most phosphorylated form of the protein. $\mathbf{b}$ Representative images of protein synthesis in sNF96.2 and ST8814 cells in the presence of drug for $24 \mathrm{~h}$. The methionine analog homoproparglyglycine (HPG) was incorporated into synthesizing proteins, and the newly synthesized proteins detected (green). White scale bar represents $50 \mu \mathrm{m}$. c, d Quantification of HPG fluorescence intensities. The graphs summarize mean \pm SD from triplicate experiments. $* * p<0.01, * * * p<0.001, * * * * p<0.0001$ (Student's $t$-test); ns $=$ not significant

synthesis assays. Upon treatment with irinotecan plus AZD2014, MPNST cells showed a profound decrease in Alexa Fluor 488 intensity, which reflects the level of 5' capdependent translation. By contrast, irinotecan alone induced no effect on protein synthesis in sNF96.2 cells and an approximate $50 \%$ decrease in ST8814 cells, while AZD2014 inhibited protein synthesis less than did the combination (Fig. 6b-d). Thus, the synergistic effect of irinotecan and AZD2014 in MPNSTs can be attributed to the ability of irinotecan to potentiate the inhibition of 
a

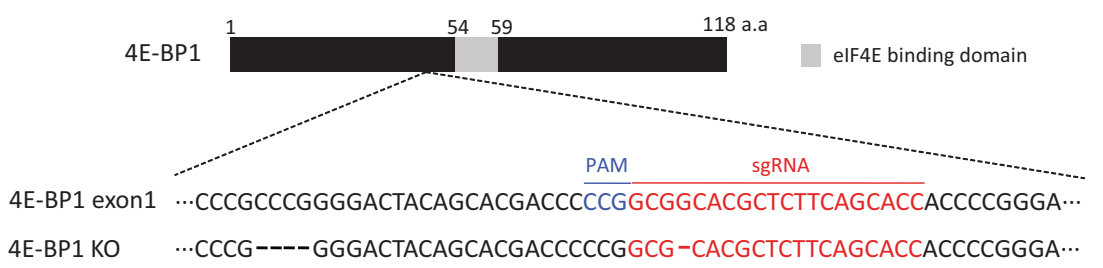

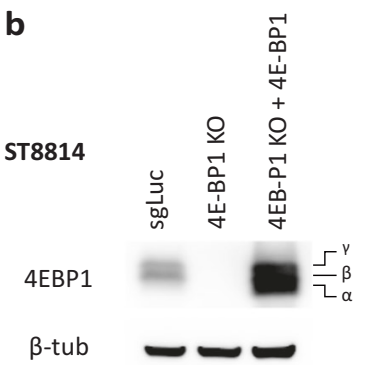

C

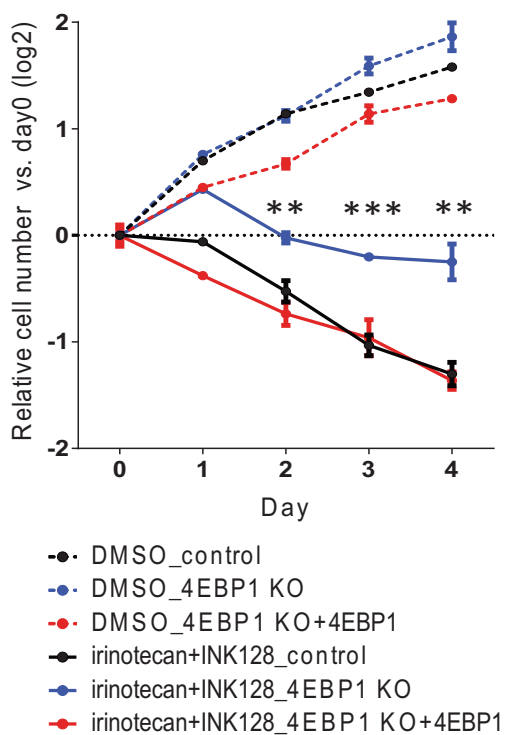

Fig. 7 Depletion of 4E-BP1 abolishes synergy of the combination of irinotecan and INK128. a The CRISPR/cas9 targeting strategy used to generate a 4E-BP1 KO ST8814 cell line. 4E-BP1 amino acid diagram and nucleotide sequences of wild-type and $\mathrm{KO}$ alleles are shown. The eIF4E-binding domain is indicated with a gray box. The binding sites for single-guide RNA (sgRNA) are marked in red, with the protospacer adjacent motif (PAM) sequence shown in blue. b Western blot for 4E-BP1 expression in control (luciferase targeting CRISPRtransfected ST8814) cells and 4E-BP1 KO; 4E-BP1 rescued the 4E-

4E-BP1 phosphorylation, resulting in a more potent block of new protein synthesis.

\section{The synergistic effect of irinotecan and INK128 is decreased in 4E-BP1 knockout cells}

If our predicted mechanism is correct, depletion of 4E-BP1 in MPNST cells should have the same effect as hyperphosphorylating 4E-BP1. Both approaches should lead to a lack of 4E-BP1 bound to eIF4E, and 5' cap-dependent translation would not be inhibited. In sum, 4E-BP1 depletion should abolish the synergy between DNA topoisomerase I-targeted drugs and mTOR kinase inhibitors in killing MPNST cells. To test this hypothesis, we used the CRISPR-cas9 system to establish a 4E-BP1 KO ST8814 cell line that harbors mutations on both alleles upstream of the eIF4E-binding domain (Fig. 7a), leading to a frameshift with early termination of d

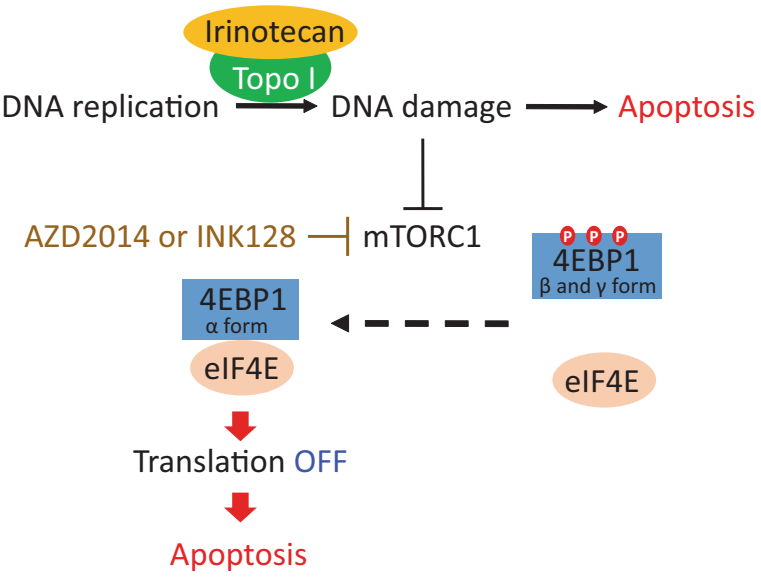

BP1-depleted cells. c Control, 4E-BP1 KO, and 4E-BP1 overexpressing 4E-BP1 KO ST8814 cells were cultured with a combination of irinotecan $(300 \mathrm{nM})$ and INK128 $(100 \mathrm{nM})$, or DMSO, and their viability was subsequently measured. Values are mean \pm SD fold changes relative to the day 0 measurement in three independent experiments. $* * p<0.005, * * * p<0.0005$ by Student's $t$-test (CRISPR control vs. 4E-BP1 KO). d Proposed mechanism by which a topoisomerase I inhibitor plus an mTOR kinase inhibitor produces synergistic activity against MPNST cells (see Discussion for details)

translation. Loss of 4E-BP1 protein expression in this line was apparent by western blotting (Fig. 7b). When evaluated against irinotecan $(300 \mathrm{nM})$ and INK128 (100 nM), the 4EBP1 KO ST8814 cells showed decreased drug sensitivity to each drug individually (Supplementary Fig. 8) and to the combination (Fig. 7c). Indeed, the synergistic cell killing of tumor cells (blue solid curve, Fig. 7c) was no longer evident, and the response to the drug combination was limited to stable disease. To validate this result, we used retroviral driven wild-type 4E-BP1 complementary DNA to rescue 4EBP1 levels, demonstrating that the cells were as sensitive as wild-type cells to treatment with irinotecan and INK128 (red solid curve, Fig. 7c). Thus, the synergy between DNA topoisomerase I-targeted drugs and mTOR kinase inhibitors in our MPNST model appears to be mediated through the mTORC1/4E-BP1 signaling pathway, which regulates the translation of cap-dependent RNAs. 
A schematic diagram illustrating the mechanism that has emerged from our biochemical studies to explain the synergistic activity of irinotecan combined with AZD2014 or INK128 is shown in Fig. 7c. The ATP-competitive mTOR inhibitor, AZD2014 or INK128 acts directly to block the mTORC1-mediated phosphorylation of 4E-BP1, and this activity is markedly augmented by combing the mTOR kinase inhibitor with a DNA topoisomerase Itargeted drug, such as irinotecan or topotecan. Unphosphorylated 4E-BP1 sequesters eIF4E, leading to a profound decrease in $5^{\prime}$ cap-dependent nascent protein synthesis, which in combination with the DNA damage response initiated by entrapped topoisomerase I synergistically induces apoptotic cell death in MPNST cells.

\section{Discussion}

Despite extensive investigation, effective chemotherapy is not yet available for unresectable MPNSTs [34-37]. Thus, to identify promising drug and pathway dependencies characteristic of MPNST, we relied on zebrafish lacking both NF1 and TP53 as a molecularly faithful preclinical model of this tumor. Our strategy is supported by the high overall molecular and genetic homologies shared by humans and zebrafish, especially for enzymes and cell surface receptors [38]. By injecting tumor cells into the fish pericardial cavity, we were able to provide a suitable microenvironment for the growth and monitoring of implanted cancer cells [39]. Thus, the fluorescence signal from the tumor mass generated by the implanted MPNST cells grew as a condensed spherical ball of cells in an anterior region of the fish embryo with minimal autofluorescence background, enabling the rapid evaluation of drug responses in live animals.

As abnormal activation of RAS by NF1 loss is a central driver event in MPNST pathogenesis [8], receptor tyrosine kinases (RTKs), including PDGFRA and EGFR, which can activate RAS signaling and downstream factors such as MEK and mTOR, are considered promising drug targets in patients with NF1-associated tumors [5, 10-12]. We therefore focused our selection of promising candidate drugs on the MEK inhibitors (selumetinib, trametinib, and PD-0325901), a pan-RTK inhibitor (sunitinib), and mTOR inhibitors (rapamycin, AZD2014, and INK128). We also tested vincristine and cyclophosphamide because of their inclusion in an effective chemotherapy regimen for softtissue sarcomas [40]. The nuclear transporter XPO1 inhibitor KPT-330 was included in the candidate list because it showed antitumor activity against MPNSTs [41], KRASdriven lung cancer [42], and T-cell acute lymphoblastic leukemia harboring activating mutations of NRAS and NOTCH1 [43]. Finally, etoposide and topotecan were considered potentially useful drugs because of their activity in the treatment of advanced soft-tissue sarcomas, alone or in combination with other agents [44, 45].

A key finding of this study was the superior single-agent activity shown by the DNA topoisomerase I-targeted drugs topotecan and irinotecan in both our zebrafish MPNST model and human MPNST cell lines. Despite the widespread use of topoisomerase I-targeted drugs for the treatment of human sarcomas, neither drug has so far been tested in a clinical trial designed for patients with MPNST. Similarly, AZD2014 showed activity in a high-throughput screen for NF2-deficient meningiomas [46], and is currently in early phase clinical trials for this disease (NCT02831257). However, this agent has not been tested for its activity in NF1-associated MPNSTs.

Targeted drugs rarely elicit prolonged responses in human cancers when given as single agents, largely because of the relatively rapid outgrowth of drug-resistant subclones during treatment. Thus, an important outcome of our study is the finding that a combination of topoisomerase I and mTOR kinase inhibitors can elicit synergistic antitumor responses in MPNST cells. Biochemical evidence of synergy was centered on the phosphorylation of $4 \mathrm{E}-\mathrm{BP} 1$, which is primarily mediated by mTORC1, and is inhibited directly by the ATPcompetitive mTOR inhibitor AZD2014. The extent of inhibition of 4E-BP1 phosphorylation increased markedly in combinations that included an mTOR kinase inhibitor and a DNA topoisomerase I-targeted drug, such as irinotecan or topotecan (Fig. 6a and Supplementary Fig. 7).

Inhibition of 4E-BP1 phosphorylation has been reported as a consequence of the DNA damage response in mouse fibroblasts and several types of human cancer cells [28, 29, 47], a result that could account for the augmented level of inhibition that we observed. Inhibition of mTOR signaling as part of the DNA damage response can result from p53-dependent pathways [28, 29] or may be a p53independent effect of activated ATM [47]. Topoisomerase I trapped on DNA by irinotecan is known to lead to DNA double-strand breaks and to stimulate a DNA damage response in tumor cells during cell cycle-mediated DNA synthesis [48, 49]. Consistent with these findings, we show increased $\gamma \mathrm{H} 2 \mathrm{AX}$ accompanied by apoptosis in MPNST cells treated with irinotecan (Supplementary Figs. 5 and 6 and Fig. 5d). Inhibition of mTOR by AZD2014 in combination with irinotecan does not appear to result in increased DNA damage as reflected by $\gamma \mathrm{H} 2 \mathrm{AX}$ levels, but does markedly increase the fraction of cells undergoing apoptosis. Presumably, the increased levels of apoptotic tumor cells induced by this drug combination are the result of enhanced sequestration of eIF4E by unphosphorylated 4E-BP1, leading to a profound decrease in $5^{\prime}$ cap-dependent nascent protein synthesis. The block of new protein synthesis combined with the DNA damage response initiated by entrapped topoisomerase I then synergistically induces apoptotic cell death in MPNST cells (see 
the conceptual model, Fig. 7d). In a broader context, 4E-BP1 phosphorylation by activated mTORC1 is a key event in the initiation of oncogenic messenger RNA translation for both cancer progression and metastasis [50]. Moreover, aberrant mTOR pathway activation is a recognized hallmark of many cancers [51]. Malone et al. [31] also reported that mTORC1 is a critical effector molecule in NF1-mutant nervous system malignancies, suggesting that a combination of topoisomerase I with an mTOR kinase inhibitor may be effective against NF1-associated tumors other than MPNSTs, such as glioblastomas, neuroblastomas, and melanomas.

A major consideration with regard to experimental models containing human tumor cells xenograted into immunosuppressed mice is that the mouse tolerates significantly greater systemic exposure to drugs such as topotecan than do human patients [52]. Dose-limiting toxicity with these agents generally stems from their antiproliferative effects on blood cell progenitors in the bone marrow. Since murine hematopoietic stem and progenitor cells (HSPCs) are much more resistant than human HSPCs in bone marrow progenitor colony-forming assays [53], mice can be dosed to much higher serum concentrations of topoisomerase I-targeted drugs than can human subjects. Thus, the responses of human xenografts growing in mice and treated at the highest dosages tolerable by normal mouse tissues have not always been reproducible in human patients. Our zebrafish allograft model of MPNST avoids this issue by relying on tumor cells and host hematopoietic cells derived from the fish. In our study, the $\mathrm{IC}_{50}$ values of topotecan in human MPNST cell lines ranged from 31 to $302 \mathrm{nM}$ (Supplementary Fig. 2), which is comparable to the $\mathrm{IC}_{50}$ values for human Ewing sarcoma, rhabdomyosarcoma, and other sarcoma cell lines- tumor types that typically show impressive clinical responses to this drug [54].

In summary, we have established a reliable and rapid in vivo assay in living zebrafish embryos to identify drugs effective against MPNSTs. Topotecan and irinotecan, both DNA topoisomerase I-targeted drugs, each showed striking activity against MPNSTs that was potentiated by the addition of an mTOR kinase inhibitor, either AZD2014 or INK128, acting through marked hypophosphorylation of 4E-BP1. These preclinical results in zebrafish embryos and human MPNST cell lines, using the combination of a DNA topoisomerase Itargeted drug with AZD2014 or INK128, merit further in vivo testing against this aggressive soft-tissue sarcoma.

\section{Materials and methods}

\section{Zebrafish lines}

Primary MPNSTs were harvested from the $n f l a+/-$; $n f 1 b-/-; p 53 \mathrm{~m} / \mathrm{m}$; sox10:mCherry zebrafish line [15], which was maintained under standard conditions as previously described [55]. As recipient fish embryos for the implantation assay, the roy and nacre, double homozygous mutant line was used, which has been named Casper [56]. All experiments involving zebrafish were approved by the Institutional Animal Care and Use Committee of the DanaFarber Cancer Institute.

\section{Embryonic implantation assay}

The embryonic implantation assay was performed as described previously [15], except that the cells were implanted in the pericardium rather than the yolk sac. See Supplementary Methods for details.

\section{Cell culture and viability assay}

sNF96.2, ST8814, S462, and 90-8TL cells were maintained in Dulbecco's modified Eagle's medium (DMEM; Gibco, 11995) supplemented with $10 \%$ heat-inactivated fetal bovine serum (Sigma-Aldrich), and $1 \%$ penicillin/streptomycin (Invitrogen). STS26T cell line was maintained in RPMI 1640 (Gibco, 11875093) medium supplemented with 5\% heat-inactivated fetal bovine serum (Sigma-Aldrich), and $1 \%$ penicillin/streptomycin (Invitrogen). See Supplementary Methods for details.

\section{Protein synthesis assay}

Protein synthesis was detected by the Click-iT HPG Alexa Fluor 488 protein synthesis assay kit (Molecular Probes, C10428). See Supplementary Methods for details.

\section{Apoptosis analysis}

To assess apoptotic cell death, we performed Annexin V-PI staining and TUNEL assay. See Supplementary Methods for details.

\section{Statistical analysis}

Statistical analysis was performed with Prism 7 software (GraphPad). See Supplementary Methods for details.

Acknowledgements We thank Dr. Donna Neuberg for biostatistical advice regarding the sample size, statistical power, and most appropriate statistical tests. We are grateful to Hillary Layden and Grace Thurston for their expert assistance with zebrafish husbandry and to Drs. Karen Cichowski and Nancy Ratner for providing human MPNST cell lines. This work was supported by the Latsis family fellowship from the Boston Children's Hospital Neurofibromatosis program, a grant from the Department of Defense (grant number W81XWH-12-10125), a Drug Discovery Initiative Award, the NF1 Research Consortium Fund, and Children's Tumor Foundation Young Investigator Award to DHK supported by the NF Research Initiative at Boston 
Children's Hospital made possible by an anonymous gift. FO acknowledges the German Cancer Aid for their generous funding within the Mildred-Scheel-Postdoctoral program of the Mildred-Scheel Foundation. ADD is a Damon-Runyon Sohn Pediatric Fellow (grant number DRSG-24-18), and acknowledges grant support from the Alex's Lemonade Stand Young Investigator Award, the American Society of Clinical Oncology Young Investigator Award and the Rally Foundation for Childhood Cancer Research Young Investigator Award.

\section{Compliance with ethical standards}

Conflict of interest The authors declare that they have no conflict of interest.

Publisher's note: Springer Nature remains neutral with regard to jurisdictional claims in published maps and institutional affiliations.

Open Access This article is licensed under a Creative Commons Attribution 4.0 International License, which permits use, sharing, adaptation, distribution and reproduction in any medium or format, as long as you give appropriate credit to the original author(s) and the source, provide a link to the Creative Commons license, and indicate if changes were made. The images or other third party material in this article are included in the article's Creative Commons license, unless indicated otherwise in a credit line to the material. If material is not included in the article's Creative Commons license and your intended use is not permitted by statutory regulation or exceeds the permitted use, you will need to obtain permission directly from the copyright holder. To view a copy of this license, visit http://creativecommons. org/licenses/by/4.0/.

\section{References}

1. Ferrari A, Bisogno G, Carli M. Management of childhood malignant peripheral nerve sheath tumor. Paediatr Drugs. 2007;9:239-48.

2. Ferner RE. Neurofibromatosis 1 and neurofibromatosis 2: a twenty first century perspective. Lancet Neurol. 2007;6:340-51.

3. Hagel C, Zils U, Peiper M, Kluwe L, Gotthard S, Friedrich RE, et al. Histopathology and clinical outcome of NF1-associated vs. sporadic malignant peripheral nerve sheath tumors. J Neurooncol. 2007;82:187-92.

4. Valentin T, Le Cesne A, Ray-Coquard I, Italiano A, Decanter G, Bompas E, et al. Management and prognosis of malignant peripheral nerve sheath tumors: the experience of the French Sarcoma Group (GSF-GETO). Eur J Cancer. 2016;56:77-84.

5. Kim A, Stewart DR, Reilly KM, Viskochil D, Miettinen MM, Widemann BC. Malignant peripheral nerve sheath tumors state of the science: leveraging clinical and biological insights into effective therapies. Sarcoma. 2017;2017:7429697.

6. Cichowski K, Jacks T. NF1 tumor suppressor gene function: narrowing the GAP. Cell. 2001;104:593-604.

7. Martin GA, Viskochil D, Bollag G, McCabe PC, Crosier WJ, Haubruck H, et al. The GAP-related domain of the neurofibromatosis type 1 gene product interacts with ras p21. Cell. 1990;63:843-9.

8. Goodsell DS. The molecular perspective: the ras oncogene. Stem Cells. 1999;17:235-6.

9. Lee W, Teckie S, Wiesner T, Ran L, Prieto Granada CN, Lin M, et al. PRC2 is recurrently inactivated through EED or SUZ12 loss in malignant peripheral nerve sheath tumors. Nat Genet. 2014;46:1227-32.

10. De Raedt T, Beert E, Pasmant E, Luscan A, Brems H, Ortonne N, et al. PRC2 loss amplifies Ras-driven transcription and confers sensitivity to BRD4-based therapies. Nature. 2014;514:247-51.
11. Jessen WJ, Miller SJ, Jousma E, Wu J, Rizvi TA, Brundage ME, et al. MEK inhibition exhibits efficacy in human and mouse neurofibromatosis tumors. J Clin Invest. 2013;123:340-7.

12. Watson AL, Anderson LK, Greeley AD, Keng VW, Rahrmann EP, Halfond AL, et al. Co-targeting the MAPK and PI3K/AKT/ mTOR pathways in two genetically engineered mouse models of schwann cell tumors reduces tumor grade and multiplicity. Oncotarget. 2014;5:1502-14.

13. Varin J, Poulain L, Hivelin M, Nusbaum P, Hubas A, Laurendeau I, et al. Dual mTORC1/2 inhibition induces anti-proliferative effect in NF1-associated plexiform neurofibroma and malignant peripheral nerve sheath tumor cells. Oncotarget. 2016;7: 35753-67.

14. Endo M, Yamamoto H, Setsu N, Kohashi K, Takahashi Y, Ishii T, et al. Prognostic significance of AKT/mTOR and MAPK pathways and antitumor effect of mTOR inhibitor in NF1-related and sporadic malignant peripheral nerve sheath tumors. Clin Cancer Res. 2013;19:450-61.

15. Ki DH, He S, Rodig S, Look AT. Overexpression of PDGFRA cooperates with loss of NF1 and p53 to accelerate the molecular pathogenesis of malignant peripheral nerve sheath tumors. Oncogene. 2017;36:1058-68.

16. Evans DG, O'Hara C, Wilding A, Ingham SL, Howard E, Dawson $\mathrm{J}$, et al. Mortality in neurofibromatosis 1: in North West England: an assessment of actuarial survival in a region of the UK since 1989. Eur J Hum Genet. 2011;19:1187-91.

17. Duong TA, Sbidian E, Valeyrie-Allanore L, Vialette C, Ferkal S, Hadj-Rabia S, et al. Mortality associated with neurofibromatosis 1: a cohort study of 1895 patients in 1980-2006 in France. Orphanet J Rare Dis. 2011;6:18.

18. Gupta G, Mammis A, Maniker A. Malignant peripheral nerve sheath tumors. Neurosurg Clin N Am. 2008;19:533-43.

19. Stucky CC, Johnson KN, Gray RJ, Pockaj BA, Ocal IT, Rose PS, et al. Malignant peripheral nerve sheath tumors (MPNST): the Mayo Clinic experience. Ann Surg Oncol. 2012;19:878-85.

20. Shin J, Padmanabhan A, de Groh ED, Lee JS, Haidar S, Dahlberg $\mathrm{S}$, et al. Zebrafish neurofibromatosis type 1 genes have redundant functions in tumorigenesis and embryonic development. Dis Model Mech. 2012;5:881-94.

21. Durbin AD, Ki DH, He S, Look AT. Malignant peripheral nerve sheath tumors. Adv Exp Med Biol. 2016;916:495-530.

22. Brohl AS, Kahen E, Yoder SJ, Teer JK, Reed DR. The genomic landscape of malignant peripheral nerve sheath tumors: diverse drivers of Ras pathway activation. Sci Rep. 2017;7:14992.

23. Charest M, Pressacco J, Thomas-Gittens J. Malignant peripheral nerve sheath tumours of the pericardium in a patient with Neurofibromatosis type 1: the diagnostic value of 18F-FDG PET-CT and I-123 MIBG SPECT-CT. J Nucl Med Technol. 2017;46:61-2.

24. Nkere UU, Walter NM. Malignant peripheral nerve sheath tumour: a rare tumour and an unusual intrapericardial presentation. Eur J Cardiothorac Surg. 1997;12:144-6.

25. Wang JC. DNA topoisomerases. Annu Rev Biochem. 1996;65:635-92.

26. Li TK, Liu LF. Tumor cell death induced by topoisomerasetargeting drugs. Annu Rev Pharm Toxicol. 2001;41:53-77.

27. Staker BL, Hjerrild K, Feese MD, Behnke CA, Burgin AB Jr., et al. The mechanism of topoisomerase I poisoning by a camptothecin analog. Proc Natl Acad Sci USA. 2002;99:15387-92.

28. Tee AR, Proud CG. DNA-damaging agents cause inactivation of translational regulators linked to mTOR signalling. Oncogene. 2000;19:3021-31.

29. Cam M, Bid HK, Xiao L, Zambetti GP, Houghton PJ, Cam H. p53/TAp63 and AKT regulate mammalian target of rapamycin complex 1 (mTORC1) signaling through two independent parallel pathways in the presence of DNA damage. J Biol Chem. 2014;289:4083-94. 
30. Choo AY, Yoon SO, Kim SG, Roux PP, Blenis J. Rapamycin differentially inhibits S6Ks and 4E-BP1 to mediate cell-typespecific repression of mRNA translation. Proc Natl Acad Sci USA. 2008;105:17414-9.

31. Malone CF, Fromm JA, Maertens O, DeRaedt T, Ingraham R, Cichowski K. Defining key signaling nodes and therapeutic biomarkers in NF1-mutant cancers. Cancer Discov. 2014;4:1062-73.

32. Haghighat A, Mader S, Pause A, Sonenberg N. Repression of capdependent translation by $4 \mathrm{E}$-binding protein 1: competition with p220 for binding to eukaryotic initiation factor-4E. EMBO J. 1995;14:5701-9.

33. Mader S, Lee H, Pause A, Sonenberg N. The translation initiation factor eIF-4E binds to a common motif shared by the translation factor eIF-4 gamma and the translational repressors 4E-binding proteins. Mol Cell Biol. 1995;15:4990-7.

34. Maki RG, D'Adamo DR, Keohan ML, Saulle M, Schuetze SM, Undevia SD, et al. Phase II study of sorafenib in patients with metastatic or recurrent sarcomas. J Clin Oncol. 2009;27:3133-40.

35. Chugh R, Wathen JK, Maki RG, Benjamin RS, Patel SR, Meyers PA, et al. Phase II multicenter trial of imatinib in 10 histologic subtypes of sarcoma using a bayesian hierarchical statistical model. J Clin Oncol. 2009;27:3148-53.

36. Schuetze SM, Wathen JK, Lucas DR, Choy E, Samuels BL, Staddon AP, et al. SARC009: Phase 2 study of dasatinib in patients with previously treated, high-grade, advanced sarcoma. Cancer. 2016;122:868-74.

37. Dickson MA, Mahoney MR, Tap WD, D'Angelo SP, Keohan ML, Van Tine BA, et al. Phase II study of MLN8237 (Alisertib) in advanced/metastatic sarcoma. Ann Oncol. 2016;27:1855-60.

38. Barbazuk WB, Korf I, Kadavi C, Heyen J, Tate S, Wun E, et al. The syntenic relationship of the zebrafish and human genomes. Genome Res. 2000;10:1351-8.

39. Zhao C, Yang H, Shi H, Wang X, Chen X, Yuan Y, et al. Distinct contributions of angiogenesis and vascular co-option during the initiation of primary microtumors and micrometastases. Carcinogenesis. 2011;32:1143-50.

40. Kroep JR, Ouali M, Gelderblom H, Le Cesne A, Dekker TJ, Van Glabbeke M, et al. First-line chemotherapy for malignant peripheral nerve sheath tumor (MPNST) versus other histological soft tissue sarcoma subtypes and as a prognostic factor for MPNST: an EORTC soft tissue and bone sarcoma group study. Ann Oncol. 2011;22:207-14

41. Nair JS, Musi E, Schwartz GK. Selinexor (KPT-330) induces tumor suppression through nuclear sequestration of IkappaB and downregulation of survivin. Clin Cancer Res. 2017;23:4301-11.

42. Kim J, McMillan E, Kim HS, Venkateswaran N, Makkar G, Rodriguez-Canales $\mathrm{J}$, et al. XPO1-dependent nuclear export is a druggable vulnerability in KRAS-mutant lung cancer. Nature. 2016;538:114-117.
43. Etchin J, Sanda T, Mansour MR, Kentsis A, Montero J, Le BT, et al. KPT-330 inhibitor of CRM1 (XPO1)-mediated nuclear export has selective anti-leukaemic activity in preclinical models of T-cell acute lymphoblastic leukaemia and acute myeloid leukaemia. Br J Haematol. 2013;161:117-27.

44. Kebudi R, Cakir FB, Gorgun O, Agaoglu FY, Darendeliler E. A modified protocol with vincristine, topotecan, and cyclophosphamide for recurrent/progressive ewing sarcoma family tumors. Pedia Hematol Oncol. 2013;30:170-7.

45. Blair SC, Zalupski MM, Baker LH. Ifosfamide and etoposide in the treatment of advanced soft tissue sarcomas. Am J Clin Oncol. 1994;17:480-4.

46. Beauchamp RL, James MF, DeSouza PA, Wagh V, Zhao WN, Jordan JT, et al. A high-throughput kinome screen reveals serum/ glucocorticoid-regulated kinase 1 as a therapeutic target for NF2deficient meningiomas. Oncotarget. 2015;6:16981-97.

47. Cam H, Easton JB, High A, Houghton PJ. mTORC1 signaling under hypoxic conditions is controlled by ATM-dependent phosphorylation of HIF-1alpha. Mol Cell. 2010;40:509-20.

48. Gilbert DC, Chalmers AJ, El-Khamisy SF. Topoisomerase I inhibition in colorectal cancer: biomarkers and therapeutic targets. Br J Cancer. 2012;106:18-24.

49. Lansiaux A, Leonce S, Kraus-Berthier L, Bal-Mahieu C, Mazinghien R, Didier S, et al. Novel stable camptothecin derivatives replacing the E-ring lactone by a ketone function are potent inhibitors of topoisomerase I and promising antitumor drugs. Mol Pharmacol. 2007;72:311-9.

50. Wang J, Ye Q, She QB. New insights into 4E-BP1-regulated translation in cancer progression and metastasis. Cancer Cell Microenviron. 2014;1:e331

51. Hanahan D, Weinberg RA. Hallmarks of cancer: the next generation. Cell. 2011;144:646-74.

52. Thompson J, Stewart CF, Houghton PJ. Animal models for studying the action of topoisomerase I targeted drugs. Biochim Biophys Acta. 1998;1400:301-19.

53. Erickson-Miller CL, May RD, Tomaszewski J, Osborn B, Murphy MJ, Page JG, et al. Differential toxicity of camptothecin, topotecan and 9-aminocamptothecin to human, canine, and murine myeloid progenitors (CFU-GM) in vitro. Cancer Chemother Pharmacol. 1997;39:467-72.

54. Cubitt CL, Menth J, Dawson J, Martinez GV, Foroutan P, Morse DL, et al. Rapid screening of novel agents for combination therapy in sarcomas. Sarcoma. 2013;2013:365723.

55. Westerfield M. The zebrafish book. A guide for the laboratory use of zebrafish (Danio rerio). 4th ed. Eugene, USA: Univ. of Oregon Press; 2000.

56. White RM, Sessa A, Burke C, Bowman T, LeBlanc J, Ceol C, et al. Transparent adult zebrafish as a tool for in vivo transplantation analysis. Cell Stem Cell. 2008;2:183-9. 